\title{
A UTILIZAÇÃO PRÉVIA DAS ODR'S EM TEMPOS DE PANDEMIA DA COVID-19 COMO REQUISITO DO INTERESSE DE AGIR
}

\author{
Lidiana Costa de Sousa Trovão ${ }^{1}$ \\ Rogerio Mollica ${ }^{2}$
}

\section{RESUMO}

A pesquisa desenvolvida analisa o instituto da Online Dispute Resolution - ODR como ferramenta alternativa e extrajudicial para autocomposição de controvérsias, a ser utilizada previamente ao ajuizamento de ação judicial. A problemática está na controvérsia de ser ou não legítima a obrigatoriedade de buscar um meio alternativo antes de ajuizar ação e de que modo representaria uma forma de obstar o acesso à justiça. Utilizou-se o método dedutivo, pesquisa bibliográfica e legislação nacional. A partir da análise dos entendimentos à luz da legislação vigente, pretende-se verificar qual situação de fato é consolidada ante à essa exigência.

PALAVRAS-CHAVE: Condições da ação. Interesse de agir. Pandemia Covid-19. Online dispute resolution. Relações de consumo.

\section{PREVIOUS USE OF ODR'S IN COVID-19 PANDEMIC TIMES AS REQUIREMENT OF INTEREST TO ACT}

\begin{abstract}
The research developed analyzes the Online Dispute Resolution - ODR institute as an alternative and extrajudicial tool for self-settlement of disputes, to be used prior to filing a lawsuit. The problem is in the controversy as to whether or not it is legitimate to have to seek an alternative means before filing an action and how it would represent a way of obstructing access to justice. The deductive method, bibliographic research and national legislation were used. From the analysis of the understandings in the light of the current legislation, it is intended to verify which situation is in fact consolidated before this requirement.
\end{abstract}

\footnotetext{
${ }^{1}$ Doutoranda (aluna especial) e Mestre em Direito no PPGD/UNIMAR. Pós-graduada em Direito Civil e Processo Civil. Professora. Advogada.

${ }^{2}$ Mestre e Doutor em Direito Processual pela USP. Professor dos Programas de Mestrado e Doutorado da UNIMAR.
} 
KEYWORDS: Action conditions. Interest in acting. Covid-19 Pandemic. Online dispute resolution. Consumer relations.

\section{INTRODUÇÃO}

Os conflitos resultantes da realização de negócios jurídicos, antes e durante o período de isolamento imprevisível ocasionado pela pandemia da COVID-19 revelaram que o ordenamento jurídico brasileiro prescinde de mais portas para solução autocomposta de resolução de conflitos. Não obstante a existência de alguns canais menos complexos, e feitos em meio ao emprego de outros canais que não os online, também constituem soluções que auxiliem a reverberar as fronteiras judiciais.

É nesse cenário que foram acirradas as discussões acerca do emprego das Online Dispute Resolutions (ODRs) como meio autocomposto de solução de conflitos, tendo como principal chamariz a oportunidade de utilização de canais diversos. Com custos reduzidos e de forma rápida, as ODRs prometem a oportunidade de que as partes possam solucionar os conflitos ocasionados pelo desfazimento, paralisação ou retardamento dos negócios realizados, que se concentram nas relações de consumo, embora não se resumam a ela.

A pesquisa propõe a discussão iniciando-se com um tópico que se dedica à análise do sistema multiportas em que estão inseridas as ODRs, no qual se aponta a possibilidade de aplicação num cenário amplo e especificamente, nesses tempos, de isolamento social. Acolhe o entendimento de que o sistema multiportas é direcionado à escolha da melhor forma possível para solução do conflito a ser enfrentado, não havendo uma única opção engessada.

Em seguida, procura apontar os requisitos para configuração do consentimento inequívoco nas relações de consumo, que, por analogia, pode ser aplicado às demais demandas que não tenham especificamente esse caráter. Decorrente desse assentimento, a aposição de cláusula de resolução online de disputas, em contrato específico, à luz da cláusula compromissória da arbitragem, as partes poderão valer-se dessa previsão para optarem pelas ODRs, em substituição.

No tópico que encerra o estudo, a análise se desloca para a concepção dada ao interesse de agir, cuja configuração tem sido exigida mediante a comprovação, pela parte, que tenha procurado resolver a situação por meio de método extrajudicial e alternativo de resolução de 
conflitos. Assim, a condição de procedibilidade estaria atrelada a esta condicionante, gerando uma série de discussões e questionamentos.

Outrossim, a pesquisa está atrelada à observância dos preceitos constitucionais e legais, assim como em atenção à doutrina e jurisprudência, sendo esta última de modo breve, porém, elucidativa. Por meio do método dedutivo, procurar-se-á descurar os principais posicionamentos acerca do tema, com o objetivo de compreender melhor as ODRs, instituto que tem sido apontado como adequado à resolução das controvérsias diante do cenário atual de pandemia do COVID-19.

\section{SISTEMA MULTIPORTAS E AS ODRS EM TEMPOS DE PANDEMIA DA COVID-19}

O sistema multiportas pressupõe a possibilidade que as partes possam escolher dentre diversas opções a que se adeque melhor aos seus anseios, e a que lhe pareça mais efetiva para a satisfação de seu pleito. Assim, dentre essas várias possibilidades, a controvérsia instalada terá mais condições de ser avaliada, de acordo com critérios processuais e da natureza da demanda, inclinando-se para uma ou outra.

A cultura da judicialização, que se tem procurado combater, está assentada na necessidade de que, assim como é dinâmica a sociedade, os conflitos gerados pelas relações humanas tenham essa mesma fluidez, sem, contudo, deixar que as pessoas sofram lesões irreparáveis. Tartuce (2018, p. 09) explica que "a substituição gradual da mentalidade contenciosa por olhares que contemplam meios extrajudiciais passa, decididamente, pela vivência de experiências proveitosas.”. O que quer dizer a autora é que é preciso experimentar as oportunidades para que, no futuro, se saiba o que realmente se adequa à realidade brasileira.

Assim, informam Pereira e Schinemann (2020, p. 03):

Conceitualmente, é possível definir meios eletrônicos de solução de conflitos como mecanismos operados por intermédio de plataformas nas quais, a partir de ferramentas automatizadas e em rede, é concedido espaço para que indivíduos em litígio, ou em risco de estabelecer litígio, possam negociar e, sendo o caso, consensualmente chegar a acordo que ponha fim à disputa.

No âmbito interno, meios alternativos ou adequados de solução de controvérsias já são utilizados juridicamente, e as ODRs nada mais são que uma possibilidade complementar às que já estão disponíveis no ordenamento jurídico-processual. O plus dado a esse tipo de mecanismo 
de autocomposição está na utilizarão da tecnologia, da virtualidade, da possibilidade que seja realizada de maneira completamente remota, reduzindo tempo e gastos com estrutura física, por exemplo.

Assim, na compreensão das Online Dispute Resolutions (ODRs) como uma as formas de autocomposição, insta mencionar os regramentos já existentes, como a Lei de Mediação e o Código de Processo Civil, cuja viabilidade jurídica foi ofertada pela Resolução n. 125/2010. Esses são os principais textos legais que trazem a previsão da mediação digital como uma das formas de autocomposição de controvérsias.

A imposição do cenário atual em relação à impossibilidade de realização de atos presenciais, mormente à já iniciada digitalização dos atos processuais deu ensejo maior à implementação das ODRs no cenário processual brasileiro. Desse modo, é possível que as partes possam resolver seus conflitos, sem que haja a necessidade de saírem de casa.

Muitos foram os desfazimentos de negócios jurídicos, especialmente aqueles que estão na seara das relações de consumo, seja pela impossibilidade temporária ou permanente do seu cumprimento. Quando ocorre a lesão ao bem da vida, a tutela judicial, alçada pela ampliação do acesso à justiça, tem sido a mais utilizada.

Nesse cenário, ante as opções para busca da solução adequada de controvérsias, a judicialização se mostra onerosa, morosa e muitas vezes ineficaz quando se trata de demandas que precisam ser solucionadas imediatamente. Não fossem as opções relacionadas à desjudicialização, atender a todos os conflitos decorrentes dessa situação de anomalia econômica e sanitária pela pandemia da Covid-19, não seria possível atendê-los nem ao menos razoavelmente.

A imbricação entre Online Dispute Resolution e a lógica do sistema multiportas, de acordo com Vasconcelos e Carnaúba (2020, p. 06) “[...] é inevitável, uma vez que a evolução nas tecnologias de comunicação implica diretamente o aumento nas alternativas de resolver as disputas, pelas mais variadas formas.”. O processo judicial eletrônico e as vídeo conferências já estão amplamente comentadas e utilizadas, e estão no contexto da utilização das novas tecnologias, entretanto, não conduzem necessariamente à uma desjudicialização.

Veja-se que as Online Dispute Resolutions (ODRs), como um desdobramento das ADRs, possibilitam que haja um auxílio e ampliação do uso da tecnologia da informação e da comunicação (information and communications technology - ICT) (PARO, 2020, p. 01). E pondera: 
[...] os métodos de ODRs podem até ter começado como métodos de ADR executados ou administrados on-line, mas o fato é que a tecnologia forneceu aos sujeitos envolvidos "novos poderes", pois possibilitou a criação de novos ambientes, inexistentes no mundo físico, a partir dos crescentes tipos de comunicação on-line que foram se fazendo disponíveis (inclusive para a esfera parojudicial, conforme o caso)

As ODRs não exigem canal específico, e essa característica amplia as possibilidades de sua utilização, num momento em que é necessário superar as dificuldades e utilizar as tecnologias disponíveis. Desse modo, é possível que a internet de um modo geral, acessada por dispositivos móveis ou fixos, por meio de aplicativos amplamente populares de troca de mensagens, como o whatsapp, ou redes sociais como o twitter auxiliem na aceitação diante de todos os públicos.

Consoante assevera Marques (2020, p. 02) “[...] os métodos de ODRs podem até ter começado como métodos de ADR executados ou administrados on-line, mas o fato é que a tecnologia forneceu aos sujeitos envolvidos "novos poderes" [...]", que faz com que se possa reconhecer a incidência da tecnologia da "quarta parte". Essa nova perspectiva, que consiste na superação das figuras do mediador, árbitro ou conciliador, faz com que surja a possibilidade de avançar no processo de resolução de disputas, sem a pressão de que um terceiro pessoalmente se posicione sobre a contenda.

Marques (2020, p. 02) explica:

Foi no conceito da tecnologia como "quarta parte" (já que o conciliador, mediador, árbitro, ou assessor das partes, quando existentes, seriam a "terceira") que se notou os maiores ganhos: no papel da tecnologia de gestão do procedimento e de estabelecimento da agenda, efetivamente guiando os litigantes a uma solução consensual, quando possível. A escolha dos meios de comunicação de forma estratégica, dessa feita, trouxe a possibilidade de se desenhar novos ambientes (e aqui vem a relação com o DSD novamente) que melhor se adaptem às circunstâncias do conflito e melhor auxiliem a dinâmica entre as partes com vistas, principalmente, a uma composição, algo que surgiu primordialmente do e-commerce.

As atividades econômicas que se lançaram na vanguarda para promover suas negociações através da internet, como os diversos tipos de comércios eletrônicos online, tiveram que buscar mecanismos para resolver os diversos conflitos que surgem naturalmente e decorrem das transações. Desse modo, canais de resolução de conflitos com uso da tecnologia 
e feitos completamente em meio virtual são um exemplo de iniciação das ODRs no Brasil, ainda que existam contextos em que a figura do mediador ainda esteja presente.

A opção pelas ODRs não obsta a judicialização dos conflitos, ainda que, em alguns casos e no entendimento de alguns juízos, haja a imprescindibilidade de buscar alguma solução extrajudicial como conditio sine qua non para que se configure o interesse de agir, conforme será tratado logo mais. Entretanto, aduzem Arbix e Maia (2020, p. 03):

Sem essencialmente alterar a prestação jurisdicional, os serviços de ADR ou a interação entre partes que visam à autocomposição, a ODR pode, nestas bases, viabilizar a conclusão de disputas, encurtar distâncias, reduzir os custos e aumentar a celeridade dos desfechos almejados pelas partes (ou a elas impostos). Exemplificam esta possibilidade a arbitragem e a mediação realizadas por videoconferência, telefone ou e-mail, sem audiências presenciais.

O real interesse que as ODRs possibilitem a autocomposição dos conflitos, além da perspectiva de que se alcance melhor eficácia do procedimento em si, a busca pela redução dos custos e do tempo oportuniza às partes que se mantenham em isolamento social e evitem aglomerações. Sendo assim, as partes " [...] pode fazer isso simplesmente ao transpor, para a internet e a telefonia móvel, os conflitos cuja resolução antes dependia de encontros presenciais entre as partes e eventuais agentes neutros, como conciliadores, mediadores, árbitros e juízes.” Arbix e Maia (2020, p. 03)

Algumas características diferenciam dos meios autocompostos das ODRs, como “[...] o baixo custo, tanto para o usuário quanto para o mantenedor da plataforma; a feição amigável ao usuário, em contrariedade à usual concepção hostil que a população no geral possui quanto às instalações de órgãos públicos; a rapidez e comodidade no atendimento; [...]”, dentre outros. (PEREIRA; SCHINEMANN, 2020, p. 03).

Nesse momento em que todos os setores da sociedade têm que se adaptar a um novo normal, em que muitos cenários foram transformados e outros, foram extintos, a aplicação das variantes de multiportas e de autocomposição podem significar alternativas reais de consolidação e ampliação de novos espaços. Na composição desse entendimento, veja-se:

A escolha dos meios de comunicação de forma estratégica, dessa feita, trouxe a possibilidade de se desenhar novos ambientes (e aqui vem a relação com o DSD novamente) que melhor se adaptem às circunstâncias do conflito e melhor auxiliem a dinâmica entre as partes com vistas principalmente a uma 
composição, algo que surgiu primordialmente do e-commerce. (PARO et al, 2020, p. 280)

Desse modo, considerando o cenário de congestionamento processual que ainda está instalado sobre o Judiciário brasileiro, e ante à possibilidade de que esse quadro venha a ser irremediavelmente agravado pelas demandas decorrentes da pandemia do Covid-19, salutar a concepção e aceitação de condições outras que promovam a desjudicialização desses contextos.

No tópico que segue a abordagem se desloca para a aferição dos requisitos para configuração do consentimento inequívoco nas relações de consumo, principal abreviatura de utilização das ODRs na atualidade, não obstante a possibilidade de que seja usada em outros conflitos. Entretanto, em tempos de conflitos de desfazimentos contratuais ocasionados pelo isolamento social obrigatório, são os consumidores os maiores afetados.

\section{REQUISITOS PARA CONFIGURAÇÃO DO CONSENTIMENTO INEQUÍVOCO NAS RELAÇÕES DE CONSUMO}

O consentimento inequívoco está dentro do espectro do negócio jurídico, como uma das condicionantes para que esse precípuo conhecimento inequívoco acerca dos elementos que compõem a transação. Trata-se, desse modo, de um dos vícios de consentimento, aquele que invalida o negócio, e tudo aquilo que dele deriva, inclusive em relação à ADR, que exige o consentimento das partes, a confidencialidade e à prevenção dos conflitos entre as partes.

Nas relações de consumo, geralmente permeados por contextos de compra e venda, é preciso reconhecer, à luz dos ensinamentos de Tartuce (2019, p. 303) que "não há defeito ou vício intrínseco à coisa. O que ocorre é vício no consentimento, consentimento defeituoso, pois o declarante acreditava que eram realmente de prata.". Nesse sentido, a título de exemplificação, "se soubesse que os candelabros não eram de prata, o comprador sequer os teria comprado [...]. O defeito, como vício de consentimento, é subjetivo, há uma falsa ideia da realidade. Em última análise, o comprador não queria comprar", de acordo com o complemento ofertado por Tartuce (2019, p. 303).

Todo esse cenário de consentimento permeia a informação, que deve estar clara, específica e inequívoca, sendo abordada no art. 30 CDC. A redação do citado artigo atrela a informação à publicidade, ou seja, a forma como o produto é demonstrado ao consumidor, e essa forma como ela se dá obriga o fornecedor que a fizer veicular ou dela se utilizar e integra 
o contrato que vier a ser celebrado. (BRASIL, 1990). Esse dispositivo incluiu todo tipo de manifestação do fornecedor que não seja considerado anúncio, mas que, mesmo assim, sirva para induzir o consentimento/decisão do consumidor.

À luz do cenário de realização de negócios jurídicos feitos virtualmente, geralmente de natureza consumerista, implica como elemento essencial a obtenção inequívoca do consentimento para que se afaste qualquer invalidade. Se realizados por meio das plataformas de comércio eletrônico, é necessário, diante disso, que se se garanta e ainda que comprove essa situação, de forma expressa e informada àquele que estiver concordando.

Nessa perspectiva, consoante pondera Amorim (2017, p. 516):

A rede mundial de computadores transformou a forma como os indivíduos celebram negócios jurídicos, desconstituindo as fronteiras físicas e desterritorializando os contratos. Nada seria mais adequado para resolver os litígios oriundos dessas relações do que utilizar os mesmos recursos que as tecnologias de informação põem à disposição dos usuários da Internet.

A regulamentação de parte desse tipo de consentimento veio através da Lei Geral de Proteção de Dados Pessoais - LGPD, que prevê que haja concordância em relação à cláusula de eleição de método online de resolução de disputas, configurando assim uma garantia entre as partes para autocomposição de eventual contenda. Esse consentimento previsto na LGPD está definido como sendo "[...] manifestação livre, informada e inequívoca pela qual o titular concorda com o tratamento de seus dados pessoais para uma finalidade determinada; [...]. (BRASIL, 2018).

É possível que, assim como pode haver a escolha de arbitragem online, do mesmo modo as partes possam optar pela ODR, desde que o façam mediante demonstração de consentimento, que só é possível diante do preenchimento dos requisitos inerentes à celebração de qualquer negócio jurídico, tal como preconiza o art. 104 do Código Civil. Do mesmo modo, compreendem o consentimento inequívoco qualquer defeito que recaia sobre ele, como aqueles relativos ao negócio jurídico, tal como evidenciam os arts. 138 a 165 do diploma civil. (BRASIL, 2002)

Mas é importante que se diga que, em relação às ODRs, para que suas decisões tenham força vinculante, deve haver o reconhecimento delas pelos tribunais nacionais, e haver alguns requisitos que configurarão a validade delas. Assim, o consentimento das partes, o devido processo legal mínimo e as garantias de transparência constituem elementos indispensáveis à 
constituição das decisões, sendo fundamentais para qualquer forma de ODR, consoante asseveram Arbix e Maia (2020, p. 04):

[...] que as tecnologias empregadas respeitem a dignidade da pessoa humana, abstendo-se de perpetuar preconceitos ou de fomentar vieses cognitivos problemáticos; que impeçam o uso iníquo da resolução de controvérsias, por exemplo, com uma alocação inadequada dos custos ou com prejuízos a terceiros alheios aos acordos e às decisões gestados; e que garantam procedimentos justos, na medida do possível mitigando assimetrias informacionais.

O consentimento inequívoco, portanto, é conditio sine qua non para que ocorra a eleição da possibilidade de utilização das ODRs para resolução de conflitos, não apenas consumeristas, não apenas online, mas ante a alternativa viável de resolução de conflito de forma remota, célere e menos onerosa.

Assim, a compreensão para que seja eleita essa possibilidade tange a colocação de cláusula de resolução de disputa em contrato específico, e constitui uma forma de proteção a ambas as partes e sobre a qual se tratará a seguir.

\section{CLÁUSULA DE RESOLUÇÃO ONLINE DE DISPUTAS EM CONTRATO ESPECÍFICO}

Os negócios jurídicos realizados em meio virtual constituem contratos executados de forma tácita cuja concordância se dá através da realização de ações virtuais e de consentimento presumido, porém, inequívoco. Para que seja possível a resolução online de disputas em contrato específico, é indispensável, como visto no tópico anterior, que as partes estejam além de cientes, sob o espeque da ausência de dúvidas acerca dessa possibilidade.

Tradicionalmente, os contratos possuem em sua estrutura cláusula de eleição de foro para resolução de eventuais conflitos, de modo que praticamente remetem à judicialização. Entretanto, a discussão se amplia quando essa eleição impede o acesso do hipossuficiente ao Judiciário, na esteira do entendimento a seguir:

AGRAVO INTERNO NO RECURSO ESPECIAL. CLÁUSULA DE ELEIÃO DE FORO EM CONTRATO DE ADESÃO. SOCIEDADE COMPOSTA DE DOIS ADVOGADOS. HIPOSSUFICIÊNCIA DEMONSTRADA FRENTE A INSTITUIÇÃO BANCÁRIA RECORRENTE. AGRAVO NÃO PROVIDO. 1. A jurisprudência desta Corte Superior possui entendimento no sentido de ser válida a cláusula de eleição de foro, que pode ser afastada quando reputada ilícita em razão de 
especial dificuldade de acesso à justiça ou no caso de hipossuficiência da parte" (AgInt no AREsp 1.178.201/SP, Rel. Ministro Luis Fellipe Salomão, Quarta Turma, julgado em 24/04/2018, DJe de 02/05/2018). 2. No caso, da análise das informações trazidas pelo Juízo a quo e pelo Tribunal, é possível concluir a hipossuficiência da sociedade de advogados frente à instituição bancária, no contrato de adesão firmado entre as partes. Desse modo, é correto o afastamento da cláusula de eleição de foro. 3. Agravo interno a que se nega provimento. (STJ, AgInt no REsp: 1583735 SP 2016/0021745-7. Rel. Min. Raul Araújo. Data Julgamento: 02/04/2019. T4 - Quarta Turma. Data da Publicação: DJe 15/04/2019).

No âmbito das cláusulas de eleição de meios alternativos de autocomposição, a mais tradicional é a cláusula compromissória, na qual as partes elegem a arbitragem para resolução de controvérsia contratual, e pode ser feita também de modo virtual, e seguirá as normas da Lei 9.307 de 23 de setembro de 1996. Em sendo a arbitragem uma forma de autocomposição de conflitos, é possível que as partes, por meio da cláusula compromissória, convencionem no sentido de comprometerem-se a submeter à arbitragem os litígios oriundos do negócio jurídico avençado.

Assim, em termos legais, o artigo $4^{\circ}$ da Lei de Arbitragem (Lei n. 9.307/96) estabelece que "a cláusula compromissória é a convenção através da qual as partes em um contrato comprometem-se a submeter à arbitragem os litígios que possam vir a surgir, relativamente a tal contrato.”. Referida cláusula, de acordo com o $\S 1^{\circ}$ do citado artigo, prevê ainda que “[...] deve ser estipulada por escrito, podendo estar inserta no próprio contrato ou em documento apartado que a ele se refira" (BRASIL, 1996).

Existem algumas preocupações que devem ter as partes quando optarem pela inserção da cláusula compromissória, conforme dimensiona Lemes (2002, p. 01):

As partes ao preverem a instância arbitral podem redigir a cláusula
compromissória como desejarem, mas devem estabelecer algumas condições
mínimas de operacionalização, tais como se a arbitragem será institucional e
neste caso será observado o regulamento da instituição nomeada (art. 4, parág.
$5^{\circ}$ ) 1 e, se for "ad hoc", a forma de indicação de árbitros, e maneira de iniciar
a arbitragem, bem como outras disposições facultativas ou suplementares, tais
como o local da arbitragem, idioma e lei aplicável (normalmente presente em
contratos internacionais), prazo para a prolação da sentença arbitral, etc.

A aplicação de cláusula contratual exclusiva que elege as ODRs como meio alternativo de solução de conflitos segue a mesma lógica, tendo em vista que se deve atenção à demanda geral vertida na regulamentação contratual civil, e desce às minúcias em relação aos meios alternativos. Nesse sentido, ante à ausência de previsão legal que aponte a diretriz em relação 
às ODRs, e dada a proximidade dos cenários e da natureza jurídica em relação à arbitragem, essa figura é utilizada como paradigma de análise à possibilidade.

Para se adequar a realidade, alguns desenhos foram traçados pela doutrina no sentido de auxiliar as partes na utilização da ferramenta multiportas, considerando o que aponta Arbix e Maia (2020, p. 06):

Para a elaboração de tais desenhos, é imprescindível o conhecimento de técnicas de mapeamento de conflitos e de construção de arranjos procedimentais, ou seja, é fundamental que a mobilização de diferentes métodos de resolução de controvérsias seja feita de forma planejada, com diagnóstico prévio dos problemas a serem endereçados e objetivos precisos a respeito deles - em geral, formulados como respostas adequadas a tais problemas.

Para consecução desse desenho, a elaboração de uma cláusula simples, a ser adotada pela empresa na formalização do negócio jurídico proposto, levada a conhecimento da parte, que deve depositar seu consentimento, ou seja, sua aderência inequívoca à utilização da ODR para resolução de eventual conflito decorrente dessa relação.

Da doutrina alienígena se colhe possíveis diretrizes para o desenvolvimento e a avaliação de sistemas de resolução de disputas, nos quais alguns fatores devem ser considerados para sua elaboração. Assim, preconizam Arbix e Maia (2020) que, no modelo proposto por Stephanie Smith e Janet Martinez, leva-se em consideração “[...] quais os tipos de conflitos em jogo e quais serão resolvidos pelo sistema; qual é o intuito central e as metas a serem atingidas; quais métodos serão adotados para prevenir, administrar e resolver conflitos [...]", dentre outros fatores.

No tópico que segue, uma das condições da ação será analisada especialmente, tendo em vista que ela tem sido considerada como imprescindível para que a ação seja processada no Judiciário. Existe uma discussão acerca dessa exigência, que permeia diversas condições, como se verá a seguir.

\section{INTERESSE DE AGIR E A EXIGÊNCIA DA PROCURA POR COMPOSIÇÃO EXTRAJUDICIAL PARA O RECEBIMENTO E PROCESSAMENTO DE AÇÃO JUDICIAL}

Configura-se o interesse de agir processual quando a parte demonstra que necessita obter, através do processo, a proteção do objeto da lide, e dele se pressupõe a lesão desse 
interesse. Marinoni et al (2016, p. 215) pontifica que o interesse de agir "decorre da necessidade de obter através do processo a proteção do interesse substancial; pressupõe, por isso, a assertiva de lesão desse interesse e a aptidão do provimento pedido a protegê-lo e satisfazê-lo.”.

Do mesmo modo que se averigua o interesse de agir como uma das condições da ação, ou seja, uma das formas de avaliar se todo o percurso a ser seguido e conduzido judicialmente terá sentido, pois, assim como os demais requisitos de procedibilidade, a interdependência entre eles é salutar. Lima $(2019$, p. 63) explica que "a prática parte do pressuposto (implícito no despacho) de que o uso de métodos alternativos ao meio tradicional de decisão adjudicada, especialmente os autocompositivos, pode ocasionar mais celeridade, efetividade e eficácia.”.

Apontado para o recorte teórico deste trabalho, assim como a perspectiva celular deste tópico, o interesse de agir tem sido discutido como uma das relevantes condições da ação, porém, condicionado à tentativa extrajudicial de autocomposição para que seja configurado. Entretanto, é salutar que esse não seja o objetivo final dos métodos alternativos de solução de conflitos, que assim como a ODR, se valha da tecnologia.

A prevenção dos conflitos judiciais, antes que esse interesse surja, é um dos alvos principais para utilização das ODRs, que busca promover uma conciliação extrajudicial, antes mesmo que ela se torne uma demanda judicializada. Nesse sentido, o posicionamento da doutrina é no sentido de que o interesse processual é o elemento que auxiliará na comprovação de que existem os requisitos mínimos para consecução da ação, sob pena de ser extinta sem resolução do mérito.

No Código de Processo Civil em vigor, o art. 17 (BRASIL, 2002) prevê que se demonstre o interesse e a legitimidade, que em sendo reconhecida, não significa que o autor tenha razão, apenas que aquele pedido merece ser apreciado. Apesar de ser uma imposição elucidativa e que afasta a judicialização desnecessária, quando se põe ao lado de outros elementos, pode significar uma condicionante do acesso à justiça, ou mesmo um empecilho desnecessário.

Cabe mencionar o postulado de Lima (2019, p. 154) em relação à limitação do acesso à justiça, “[...] a prática objetiva que - diante de um cenário de crescente judicialização de todo e qualquer conflito de interesse - seja comprovado que a pretensão é resistida, ou seja, haja comprovação do interesse de agir.". A obrigatoriedade de que se esgotem as vias extrajudiciais para consecução de um processo judicial, é exigido da parte a fim de que, “[...] ao procurar o 
Poder Judiciário para buscar a tutela jurisdicional, esteja configurada a efetiva impossibilidade de a parte obter, por si própria, a situação almejada”. (TARTUCE, 2018, p. 13).

Cabe destacar que a imposição de demonstração de busca por prévia tentativa de resolução via métodos extrajudiciais não constitui requisito para aferir a regularidade da petição inicial, como é sabido, embora haja a necessidade de comprovação da pretensão resistida ou interesse de agir é requisito processual. Esta comprovação, por seu turno, não se limita à busca pelas ODRs, ou qualquer outro tipo de autocomposição, mas pode ser demonstrado por meios mais simples, como negociações por telefone, como assevera Lima (2019, p. 158):

[...] todos os meios legais podem ser utilizados para a comprovação prévia do interesse de agir, como áudios de atendimento em call centers dos fornecedores, troca de correspondências eletrônicas entre as partes, termos de reclamações realizadas nos Procons, gravações de áudios de conversas telefônicas, dentre outras infinidades de formas.

Nesse ponto, cabe uma reflexão interessante. O Conselho Nacional de Justiça, a partir da Resolução n. 125/2010, ampliou os incentivos à busca por meios consensuais de solução de conflitos, objetivando assim, que fossem alargadas as possibilidades de que o cidadão pudesse pôr fim a uma contenda, seja ela por meio do Judiciário ou não. Trata-se, nesse sentido, de um contexto muito mais aproximado da efetivação dos direitos fundamentais, que seguiu com a dinâmica promovida pelo Código de Processo Civil de 2015.

Há, portanto, um novo modelo de acesso à justiça, no qual as pessoas podem buscar resolução para seus conflitos sem necessariamente ter que ajuizá-lo. Nesse sentido, Figueiredo (2020, p. 21) explica que "[...] isso ocorre porque o acesso à justiça está mais ligado à satisfação do jurisdicionado com a resolução de conflito - obtenção do bem da vida pretendido - do que com o mero acesso ao Poder Judiciário.”.

Superada do eventual acesso condicionado à Justiça, a questão analisada se desloca para o que a jurisprudência tem dito acerca da extinção dos processos sem resolução do mérito, a exemplo do que vem sendo visto nas decisões proferidas pelo Tribunal de Justiça de São Paulo, a saber:

Ação indenizatória - Atraso de voo - Suspensão do processo para que a autora promova a tentativa de conciliação, por meio do portal do consumidor, sob pena de extinção do processo por falta de interesse de agir Impossibilidade Não se pode condicionar o acesso à justiça à necessidade de prévia utilização 
ou exaurimento da via administrativa, sob pena de ofensa aos princípios constitucionais, principalmente, ao da inafastabilidade da jurisdição Recurso provido. (TJ/SP. AI/SP n. 2051721-59.2020.8.26.0000. Rel. Souza Lopes. 17 Câmara de Direito Privado. Data do julgamento: 23/06/2020. Data da publicação: 23/06/2020.)

Essa linha jurisprudencial de acordo com entendimentos recentes, deve ser levada em consideração, a fim de se afastar o acionamento desnecessário do Judiciário. Diante desse entendimento é que se pode conceber em que medida os meios consensuais atingem seu objetivo, pois, estando à disposição das partes, é legítimo ao magistrado exigir que os demandantes procurem anteriormente os meios alternativos/adequados de solução de conflitos.

Entretanto, em tempos de pandemia, assim como o julgado acima citado, o Tribunal de Justiça de São Paulo tem condicionado as partes à procura pela plataforma consumidor.gov, como meio autocomposto de solução de controvérsia, determinado a suspensão do processo, e não o extinguindo de plano, conforme se vê no julgado colacionado abaixo:

Agravo de instrumento - Ação revisional de contrato bancário. Decisão que suspende o feito, pelo prazo de 30 dias, determinando à autora o registro de reclamação na ferramenta "consumidor.gov", comprovando a providência Agravo recebido aplicando-se entendimento consolidado no REsp 1696396/MT - Impossibilidade de suspensão do feito por causa estranha àquelas constantes do rol do artigo 313 do CPC - Embora louváveis tentativas de solução consensual da lide, ao autor não cabe imposição de providências que extrapolem o âmbito processual Consumidor que não é obrigado a esgotar meios administrativos para a propositura de ação judicial, considerando que o acesso ao Judiciário é inafastável e absoluto Recurso provido, confirmandose liminar nele concedida. (TJ/SP. AI/SP n. 2040989-19.2020.8.26.0000. Rel. Claudia Grieco Tabosa Pessoa. 19a Câmara de Direito Privado. Data do julgamento: 11/05/2020. Data de publicação: 11/05/2020.)

Há quem entenda, num contexto geral, que o "interesse de agir, condição da ação representada, em síntese, pelo binômio necessidade/utilidade da tutela jurisdicional e cuja interpretação, excessivamente ampla, é de ser revista.”. (LEMKE, 2014, meio eletrônico). A autora sustenta ainda:

É essencial que o Poder Judiciário não se deixe impressionar com esse fato ou com o argumento da "economia processual", segundo o qual sempre que o autor venha a juízo é o caso de apreciar o mérito de seu pedido, para evitar que ele tenha de fazer o prévio requerimento administrativo e eventualmente voltar ao Poder Judiciário, no caso de o seu pedido vir a ser indeferido, posteriormente, pelo ente estatal. Esse tipo de raciocínio, que certamente serve muito bem para resolver o caso concreto, cria um problema para o sistema judicial, pois as partes, muitas vezes, preferem se dirigir diretamente ao Poder 
Judiciário, principalmente se puderem gozar do benefício da assistência judiciária gratuita, ao invés de dirigir o seu pedido previamente à Administração, o que acaba por transformar o Poder Judiciário quase que em uma repartição administrativa em algumas áreas, com graves consequências em relação ao incremento do número de processos em tramitação.

É interessante o entendimento da autora, pois a inviabilidade de buscar o Judiciário se dá quando se fecha uma das "portas" para esse acesso. Há pessoas que preferem, dentre as portas disponíveis, a do Judiciário, e impedir que seja feita essa escolha, é obstar o acesso à justiça e tangencia a seara das liberdades tão consagrada no texto constitucional.

A consideração acerca dos demais pontos que compõem a questão implicam a uma opção a utilização dos métodos de solução de controvérsias, não havendo nenhuma questão de antecedência lógica quando colocada à apreciação do Judiciário. Desse modo, há “apenas uma preferência quanto à utilização de um método de solução de controvérsias ou de outro e, muitas vezes, se o método não for adjudicatório, sequer se verificará uma demanda.” (LIMA, 2019, p. 111).

Em complemento, aduzem Costa e Francisco (2020, p. 01):

Ainda que se parta da correta concepção de que meios consensuais de resolução de conflito podem propiciar acesso à justiça mais amplo, quando adequados às particularidades da causa, dela não decorre, necessariamente, a conclusão de que é necessária a comprovação da "pretensão resistida" pelo réu, para se reconhecer o interesse de agir que autoriza a propositura da demanda judicial pelo autor.

Como se vê, existem diversos pontos que devem ser levados em consideração ao analisar o interesse de agir numa demanda em que o autor não leva a conhecimento do magistrado a prévia utilização de um meio alternativo de solução de controvérsia. Ao mesmo tempo em que o interesse de agir é condição de procedibilidade, ela não importa no conhecimento do mérito da ação, e nesse sentido, parece prematura a extinção do processo sem resolução do mérito ao se analisar apenas um dos pontos existentes.

Além disso, consoante mencionado acima, as ODRs podem ter pontos de divergência na escolha pelo aludido método, consoante aponta a pesquisa de Navarenho (2019, p. 35):

Com relação aos dezesseis respondentes que marcaram que a ODR não pode substituir a presença de um mediador humano, sete mencionaram que acreditam que será difícil a tecnologia substituir totalmente da presença humana, devido à complexidade de certos processos, e pela força existente na oralidade e no contato pessoal. Mencionou-se também a possibilidade das 
pessoas de agirem de forma diferente na presença de uma sala digital, dificultando assim a relação de transparência entre as pessoas nesta situação.

Nessas condições, as Online Dispute Resolutions, ou simplesmente ODRs, possuem um alcance limitado ao serem consideradas únicos meios de resolução de conflitos e com determinação em si, destoando o conceito multiportas. Cabe mencionar que esse contexto reducionista, ou de imposição de busca por esse canal para que a partir de então se chegue ao Judiciário, não condiz com os objetivos consensuais e processuais primitivos, pois deste modo, estarão sendo usadas duas portas para tentativa de resolução de um único conflito.

No âmbito brasileiro, apesar de ser em parte compreensível o posicionamento embasado na falta de interesse de agir, sua prevalência não tem sido verificada nos tribunais pátrios. Tartuce (2018, p. 13) observa:

O prestígio à autocomposição decididamente prevaleceu nas recentes mudanças legislativas: a realização de uma sessão consensual inicial está prevista tanto no Código de Processo Civil de 2015 como na Lei de Mediação (Lei $\mathrm{n}^{\mathrm{o}}$ 13.140/2015) - mas o legislador não chegou ao ponto de condicionar o ingresso no Poder Judiciário à demonstração de prévia tentativa consensual.

Desse modo, não pode o magistrado impor, ao seu alvedrio, que os requisitos essenciais apostos em ambas as leis para o recebimento da ação e consequente citação do réu esteja condicionado à essa situação anterior. Ante a esse cenário, Tartuce (2018, p. 14) pontifica que "a previsão indica que a tentativa de autocomposição não foi eleita pelo sistema como um elemento essencial do 'interesse de agir', mas sim que seu fomento se dará a partir do estabelecimento da sessão consensual como uma etapa prioritária do processo.”.

Além disso, o próprio CPC aponta condicionantes à realização da tentativa de autocomposição, ao mencionar que se ambas as partes manifestarem expressamente seu desinteresse ou mesmo se os direitos em discussão não admitirem autocomposição, a audiência não será realizada. (TARTUCE, 2018). Do mesmo modo, a previsão de que a ausência do autor à audiência de conciliação não acarreta a extinção do processo sem resolução do mérito.

Assim, o principal argumento para que seja exigida a tentativa de autocomposição anterior ao ajuizamento da ação está assentada no fato de que as partes devem evitar a judicialização, bem como afastar as demandas desnecessárias, primando sempre pela celeridade e não onerosidade. No caso específico das ODRs, em tempos de pandemia, os interessados devem optar pelos canais que proporcionem o isolamento social. 
De outro lado, igualmente fortes, os argumentos contrários à dura extinção do processo sem resolução do mérito com base no fundamento apontado, significaria obstar o acesso à justiça, reduzindo as opções multiportas, bem como, restringindo os direitos fundamentais no campo das liberdades individuais. Além disso, a ausência de previsão legal, mormente à ausência de regulamentação do procedimento das ODRs, aplaina os argumentos e devolve ao intérprete a exegese da melhor alternativa para cada caso.

Sem dúvida, o congestionamento do Judiciário imprescinde de métodos alternativos, e o ajuizamento de demandas desnecessárias devem ser rechaçadas diante de um poder já aniquilado pelo gargalo de anos. Como a maioria dos institutos comportam temperamentos, e esse exercício, de fato, não é dos mais fáceis, a procura pelo equilíbrio permanecerá.

\section{CONCLUSÃO}

Há muito se tem discutido acerca da desjudicialização das demandas e o albergue dos meios autocompostos de solução de conflitos como uma das alternativas multiportas postas ao socorro de que se sentir lesado. Sobretudo com o advento do Código de Processo Civil e a Lei de Mediação, tem se configurado o obstinado intento de afastar as demandas da apreciação do Judiciário, exatamente pela ausência da eficácia da prestação jurisdicional.

Não obstante, as próprias partes têm se inclinado no sentido de buscar melhores condições de procedibilidade de seus conflitos, mormente à resistência de parte da população em conceber novas formas de solução de controvérsias, talvez arraigados pela cultura da judicialização. Ainda assim, a carência de meios autocompostos é sensível de tal modo que as discussões se intensificam diante de crises como as que está sendo enfrentada, de isolamento social cuja obrigatoriedade sanitária de que só se tenha contato pessoal quando estritamente necessário.

Nesse sentido, a pesquisa revelou que as Online Dispute Resolutions - ODRs trazem uma proposta de acesso fácil e remoto, gratuito (ao menos inicialmente) e de resolução rápida, sem a necessidade de atuação de um árbitro, mediador ou qualquer figura semelhante. Ainda que se posicione à luz dos contextos utilizados fora do país, a possibilidade de sua utilização foi verificada principalmente em face de negócios jurídicos feitos em meio virtual.

Contudo, a exploração feita em relação à exigência de que a parte busque previamente a resolução da contenda como requisito de configuração do interesse de agir tem recebido 
diversas críticas, dentre elas, a que a associa a uma possível obstrução ao acesso à justiça. Dela, decorrem outros apontamentos contrários, mas o que se destaca, de fato, é que ao indivíduo se estaria restringindo a liberdade de escolha assentada no contexto das múltiplas portas.

Mas o que de fato ficou evidenciado é que nenhum dos meios será totalmente anatômico a todas as situações. É preciso levar em consideração, principalmente nesses tempos de pandemia do COVID-19, que as pessoas possam ter o socorro de que necessitam e que a façam por meio seguro, dentro dos parâmetros sanitários impostos. Além disso, que esse meio reúna as características mínimas para alcançar esse objetivo, que é o caso das ODRs.

Não se verificou nos elementos constitutivos das ODRs nenhum elemento que seja contrário ao ordenamento jurídico, nem que seja contrário à ordem pública, ou que enseje prejuízo irreparável às partes. Desse modo, não há óbice à sua aplicação, e é um modo que se mostra adequado à autocomposição de demandas durante a pandemia, ainda que parte do seu público opte pela judicialização, ou mesmo que não seja hipossuficiente aos meios digitais.

\section{REFERÊNCIAS}

AMORIM, Fernando Sérgio Tenório de. A resolução online de litígios (odr) de baixa intensidade: perspectivas para a ordem jurídica brasileira. Pensar - Revista de Ciências Jurídicas. Fortaleza, v. 22, n. 2, p. 514-539, maio/ago. 2017. Disponível em: https://periodicos.unifor.br/rpen/article/view/5397/pdf. Acesso em: 23 set. 2020.

ARBIX, Daniel; MAIA, Andrea. Uma introdução à resolução on-line de disputas. Revista de Direito e as Novas Tecnologias - RDTEC. São Paulo, v. 3, n. 01, p. 1-13, abr./jun. 2019.

BRASIL. Lei n. 8078, de 11 de setembro de 1990. Disponível em: http://www.planalto.gov.br/ccivil_03/leis/18078compilado.htm. Acesso em: 23 set. 2020.

BRASIL. Lei 9307, de 23 de setembro de 1996. Disponível em: L9307 (planalto.gov.br). Acesso em 23 set. 2020.

BRASIL. Lei 10.406, de 10 de janeiro de 2002. Disponível em: http://www.planalto.gov.br/ccivil_03/leis/2002/110406compilada.htm. Acesso em: 23 set. 2020.

BRASIL. Lei n. 13709, de 14 de agosto de 2018. Disponível em: L13709 (planalto.gov.br). Acesso em: 23 set. 2020.

COSTA, Susana Henrique da; FRANCISCO, João Eberhardt. Acesso à justiça e a obrigatoriedade da utilização dos mecanismos de online dispute resolution: um estudo da plataforma consumidor.gov. In: LUCON et al. Direito, Processo e Tecnologia. São Paulo: 
Revista dos Tribunais, 2020. Disponível em:

https://proview.thomsonreuters.com/launchapp/title/rt/monografias/235813054/v1/page/III.

Acesso em: 15 set. 2020.

FIGUEIREDO, Bianca Fernandes. Consumidor.gov.br: a exigência de utilização da plataforma digital de solução adequada de conflitos antes do ajuizamento de ação de consumo como fator de eficiência do Poder Judiciário, à luz da análise econômica do direito. Revista CNJ. Brasília, 4, n. 1, p. 17-36, jan/jul 2020. Disponível em: https://www.cnj.jus.br/ojs/index.php/revista-cnj/article/view/98. Acesso em: 24 set. 2020.

LEMES, Selma M. Ferreira. Cláusulas arbitrais ambíguas ou contraditórias e a interpretação da vontade das partes. 2012. Disponível em:

http://selmalemes.adv.br/artigos/artigo_juri32.pdf. Acesso em: 24 set. 2020.

LEMKE, Gisele. O congestionamento do Poder Judiciário: um breve estudo sob o ponto de vista da demanda dos serviços judiciais. Revista de Doutrina da $4^{\mathbf{a}}$ Região. Porto Alegre, n. 58, fev. 2014. Disponível em:

<https://revistadoutrina.trf4.jus.br/artigos/edicao058/Gisele_Lemke.html>

Acesso em: 24 set. 2020.

LIMA, Daniel Henrique Sprotte. Da cultura do litígio à do consenso: o uso de Online Dispute Resolution na Comarca de Araquari (SC). Dissertação submetida ao Programa de Pós-Graduação em Direito da Universidade Federal de Santa Catarina para a obtenção do Grau de Mestre em Direito. Florianópolis: UFSC, 2019.

MARINONI, Luiz Guilherme. Novo curso de processo civil [livro eletrônico]: teoria do processo civil. São Paulo: Editora Revista dos Tribunais, 2016.

MARQUES, Ricardo Dalmaso. A Resolução de Disputas Online (ODR): do comércio eletrônico ao seu efeito transformador sobre o conceito e a prática do acesso à justiça. Revista de Direito e as Novas Tecnologias - RDTEC. São Paulo, v. 5, n. 4, p. 1-27, out./dez. 2019.

NAVARENHO, Vinicius de Souza. Aplicação da inteligência artificial no âmbito jurídico. Brasília: UnB, 2019. Disponível em: https://bdm.unb.br/handle/10483/23110. Acesso em: 24 set. 2020.

PARO, Giácomo. et al. On-line Dispute Resolution (ODR) e o interesse processual. In: LUCON et al. Direito, Processo e Tecnologia. São Paulo: Revista dos Tribunais, 2020. Disponível em: https://proview.thomsonreuters.com/launchapp/title/rt/monografias/235813054/v1/page/III. Acesso em: 22 set. 2020.

PEREIRA, Luís Fernando Casagrande; SCHINEMANN, Caio César Bueno. On-line dispute resolution no processo civil brasileiro: o caso das plataformas de indenização contra companhias aéreas. In: LUCON et al. Direito, Processo e Tecnologia. São Paulo: Revista dos Tribunais, 2020. Disponível em:

https://proview.thomsonreuters.com/launchapp/title/rt/monografias/235813054/v1/page/III. Acesso em: 22 set. 2020. 
STJ. Superior Tribunal de Justiça. AgInt no REsp: 1583735 SP 2016/0021745-7. Rel. Min. Raul Araújo. Data Julgamento: 02/04/2019. T4 - Quarta Turma. Data da Publicação: DJe 15/04/2019. Disponível em: https://stj.jusbrasil.com.br/jurisprudencia/859551603/agravointerno-no-recurso-especial-agint-no-resp-1583735-sp-2016-0021745-7?ref=serp. Acesso em: 24 set. 2020 .

TJ/SP. Tribunal de Justiça de São Paulo. AI/SP n. 2051721-59.2020.8.26.0000. Rel. Souza Lopes. $17^{\text {a }}$ Câmara de Direito Privado. Data do julgamento: 23/06/2020. Data da publicação: 23/06/2020. Disponível em:

https://esaj.tjsp.jus.br/cjsg/getArquivo.do?conversationId=\&cdAcordao=13678914\&cdForo= 0\&uuidCaptcha=sajcaptcha 30394533ba6040bd8cf1c13e840914fd\&g-recaptcharesponse=03AGdBq27Qc4Z6p6zhHcYcLKJHg1sOEZ8aAbgaxcLZ-Qver0VBP3y5Yy6eP1JjxfkPycm1cXmbXCQhQaJsaEec1_wljjg--2JPcq2mlFK7rqgabxf-BJp3Py5C7eWSNB_3_DJqBiGKiiT7tDbCQuW8N-SsCAOGguhvfAMUF-wCCyp0qNjAeh3qQPfvamtSFmeqeNPgaBGV_8amCmu9H8_HGP7y4eSH9hhBm3SndYBuENLAsK4Z290 U7t4DVc3nLGIWIwE2m65mI8skdJCTdBS-8rqtF0eOMEu3XRowgrwROGbj8KuRZEX5Zu 3o3FeiaMeHxszP8NAPtUdRFuD3IRUJSTQ7iZc3lo6JAh7f2hWcKcslWxNo6zXXiwiEfQCHzboJWaUGRUVcL2uOHyiRPOIVrdh8 vd71ctgcd0J1sVo0M8qcJud07Na50wR0Qyp-ogblI37gtQiKHl8nCx61OhMlgJwBdERMeh2VHiABCmhf7oGo0n gRFxqxJlOIEBxjKxYFxN1M. Acesso em: 25 set. 2020 .

TJ/SP. Tribunal de Justiça de São Paulo. AI/SP n. 2040989-19.2020.8.26.0000. Rel. Claudia Grieco Tabosa Pessoa. 19a Câmara de Direito Privado. Data do julgamento: 11/05/2020. Data de publicação: 11/05/2020. Disponível em: https://esaj.tjsp.jus.br/cjsg/getArquivo.do?cdAcordao=13544854\&cdForo=0. Acesso em: 25 set. 2020.

TARTUCE, Fernanda. Mediação de conflitos: proposta de emenda constitucional e tentativas consensuais prévias à jurisdição. Revista Magister de Direito Civil e Processo Civil. Brasília, v. 14, n. 82, p. 5-21, jan./fev. 2018. Disponível em: https://www.tjdft.jus.br/institucional/biblioteca/conteudo-revistas-juridicas/revista-magisterde-direito-civil-e-processual-civil/2018-v-14-n-82-jan-fev. Acesso em: 17 set. 2020.

TARTUCE, Flávio. Direito Civil: teoria geral dos contratos e contratos em espécie. Rio de Janeiro: Forense, 2019.

VASCONCELOS, Ronaldo; CARNAÚBA, César Augusto Martins. Custos de transação do processo e Online Dispute Resolution: um sistema multiportas 4.0 economicamente eficiente. In: LUCON et al. Direito, Processo e Tecnologia. São Paulo: Revista dos Tribunais, 2020. Disponível em:

https://proview.thomsonreuters.com/launchapp/title/rt/monografias/235813054/v1/page/III. Acesso em: 22 set. 2020. 